\title{
Multiple Disease Resistance Loci Affect Soilborne Disease Resistance in Tobacco (Nicotiana tabacum)
}

\author{
Katherine Drake-Stowe, Nicolas Bakaher, Simon Goepfert, Berangere Philippon, Regis Mark, Paul Peterson, \\ and Ramsey S. Lewis ${ }^{\dagger}$
}

First and seventh authors: Crop and Soil Science Department, North Carolina State University, Raleigh; second, third, fourth, and fifth authors: Philip Morris International R\&D, Philip Morris Products S.A., Neuchatel, Switzerland (part of Philip Morris International group of companies); and sixth author: Pee Dee Research and Education Center, Clemson University, 2200 Pocket Rd., Florence, SC.

Accepted for publication 31 May 2017.

\begin{abstract}
Phytophthora nicotianae and Ralstonia solanacearum are two of the most important pathogens affecting tobacco worldwide. Greater insight regarding genetic systems controlling resistance to these two soilborne pathogens, as well as identification of DNA markers associated with genomic regions controlling this resistance, could aid in variety development. An evaluation of 50 historical tobacco lines revealed a high positive correlation between resistances to the two pathogens, preliminarily suggesting that some genomic regions may confer resistance to both pathogens. A quantitative trait loci (QTL) mapping experiment designed to investigate the genetic control of soilborne disease resistance of highly resistant ' $\mathrm{K} 346$ ' tobacco identified four QTL significantly associated with resistance to P. nicotianae (explaining
\end{abstract}

ABSTRACT
$60.0 \%$ of the observed phenotypic variation) and three QTL to be associated with $R$. solanacearum resistance (explaining 50.3\% of the observed variation). The two QTL with the largest effect on Phytophthora resistance were also found to be the QTL with the greatest effects on resistance to Ralstonia. This finding partially explains previously observed associations between resistances to these two pathogens among U.S. current cultivars and within breeding populations. Further study is needed to determine whether these relationships are due to the same genes (i.e., pleiotropy) or favorable coupling-phase linkages that have been established over time.

Additional keywords: bacterial wilt, black shank, Nicotiana.
Black shank and bacterial wilt, caused by the soilborne pathogens Phytophthora nicotianae and Ralstonia solanacearum, respectively, are the most important diseases affecting tobacco production in many parts of the world. Strategies used to reduce economic loss from both diseases include crop rotation, chemical inputs, and the use of genetic resistance. Genetic resistance is usually the most cost-effective component of integrated disease management systems if it can be incorporated into cultivars without adversely affecting yield or cured leaf quality.

A number of sources of genetic resistance to black shank have been investigated but no known source provides complete resistance to all races of the black shank pathogen. Monogenic resistance conferred by the $P h p$ and $P h l$ genes has been introgressed from Nicotiana plumbaginifolia (Apple 1962; Chaplin 1962) and N. longiflora (Valleau et al. 1960), respectively. These genes provide immunity only to race 0 of $P$. nicotianae. Very high levels of resistance to both race 0 and race 1 of the black shank pathogen have also been associated with an introgressed $N$. rustica region designated as $W z$ (Drake and Lewis 2013; Drake et al. 2015). Widespread adoption of varieties containing either $P h p$ or $P h l$ has been shown to lead to pathogen race shifts and the ultimate predominance of alternative races (Sullivan et al. 2005). It is possible that $P$. nicotianae populations may also rapidly adapt to $W z$ (K. L. McCorkle, K. E. Drake-Stowe, R. S. Lewis, and H. D. Shew, unpublished data). Because of low durability of monogenic resistance mechanisms, tobacco breeders should focus on combining monogenic resistance with medium to high levels of polygenic resistance, which tends to be more durable over time.

Based on historical pedigree information, most polygenic black shank resistance in flue-cured and burley tobacco is believed to have

†Corresponding author: R. S. Lewis; E-mail: ramsey_lewis@ncsu.edu

*The $\boldsymbol{e}$-Xtra logo stands for "electronic extra" and indicates that one supplementary figure is published online.

(c) 2017 The American Phytopathological Society been derived from 'Florida 301' cigar tobacco (Tisdale 1931). However, no comparison has been made between black shank resistance quantitative trait loci (QTL) discovered to control resistance in Florida 301 and those found to influence resistance in modern U.S. flue-cured tobacco. It is known, however, that this type of resistance is of the classic polygenic type, where resistance is partial, controlled by multiple genes, and nonrace specific (Chaplin 1966; Smith and Clayton 1948; Xiao et al. 2013).

Considerably less is known about genetic resistance of $N$. tabacum to bacterial wilt. This is likely due to greater sensitivity of $R$. solanacearum to environmental conditions and also large differences in pathogenic potential of various strains (Katawczik and Mila 2012). Strains of $R$. solanacearum isolated from tobacco and tomato across the southeastern United States have been classified as race 1, biovar 1, and belong to phylotype II (Hong et al. 2012; Katawczik et al. 2016). Resistance from $N$. tabacum germplasm accession TI 448A has been described as polygenic in nature and is reported to be the primary source of bacterial wilt resistance incorporated into U.S. flue-cured tobacco cultivars (Smith and Clayton 1948; Valleau 1952). The Rps and Rxa genes have also been described and reportedly utilized by Japanese tobacco breeders (Matsuda 1977; Matsuda and Ohashi 1973), although the system used to identify and declare the presence of these genes is not clear.

There is anecdotal evidence of a correlation between genetic resistance to black shank and bacterial wilt in tobacco, because many flue-cured commercial cultivars that exhibit high levels of resistance to black shank also display medium to high levels of resistance to bacterial wilt, and vice versa (North Carolina Cooperative Extension 2015). Taken alone, these observations do not indicate that the same genes or genomic regions controlling resistance to one disease also affect resistance to the second disease. Such a genetic relationship is possible, however, and the subject of plant genomic regions controlling multiple disease resistance (MDR) has recently become of increased interest (Wiesner-Hanks and Nelson 2016). 
Mapping of QTL can be used to identify $N$. tabacum genomic regions that influence resistance to both $P$. nicotianae and $R$. solanacearum. Previous mapping studies have identified QTL controlling black shank resistance in highly resistant 'Beinhart 1000' (Vontimitta and Lewis 2012a,b) and Florida 301 (Xiao et al. 2013) cigar tobacco. The objective of the current research was to further investigate the genetic basis of soilborne disease resistance in N. tabacum. First, a set of 50 tobacco lines of historical breeding importance was evaluated in replicated testing over multiple environments for resistance to both black shank and bacterial wilt to gain preliminary insight into the correlation between these two traits. Second, we studied the correlation between resistance to these two diseases using a recombinant inbred line (RIL) population derived from a cross between disease-susceptible tobacco accession 'TI 1068' and 'K346,' a representative of U.S. flue-cured tobacco cultivars that exhibits very high levels of resistance to both black shank and bacterial wilt. Comparison of QTL identified for resistance to each disease was used to identify genomic regions carrying alleles that influence multiple disease resistance. Finally, we determined the extent to which QTL significantly associated with black shank resistance in modern K346 tobacco overlap with those previously identified to control resistance in Florida 301, the reported source of polygenic black shank resistance in modern U.S. tobacco. Comparisons may be of value in connection with future work to exploit cigar tobacco germplasm as a resource for black shank resistance in flue-cured and burley tobacco.

\section{MATERIALS AND METHODS}

Genetic materials and disease evaluations. A set of 50 tobacco genotypes was selected to study the phenotypic ranges and correlations for resistance to black shank and bacterial wilt (Table 1). The set of lines included Florida 301 and 'TI 448A', the reported sources of soilborne disease resistance in flue-cured tobacco. Eight old-line cultivars were selected to represent fluecured tobacco germplasm prior to the initiation of science-based plant breeding to improve soilborne disease resistance. Also included were 39 flue-cured tobacco varieties of historical importance that represented decades of tobacco improvement from the 1940s to the 1990s. No hybrids were included and no varieties carrying the $P h p$ gene were included, because the primary interest was to study polygenic resistance. Finally, Beinhart 1000 was included in the set of 50 lines as a genotype that exhibits exceptionally high levels of polygenic resistance to black shank. These 50 lines were evaluated for black shank resistance at two North Carolina locations naturally infested with the black shank pathogen (Lower Coastal Plain Research Station, Kinston, NC and Upper Coastal Plain Research Station, Rocky Mount, NC) in 2010 and 2011 (for a total of four environments). The set of 50 lines was also evaluated for bacterial wilt resistance in a disease nursery at the Upper Coastal Research Plain Research Station during 2014 and 2015; a bacterial wilt field nursery at the Pee Dee Research and Education Center at Florence, SC during 2015; and in a naturally infested private farm field near Selma, NC during 2015 (for a total of four environments). The experimental design for each environment was a randomized complete block design with three replications. Experimental units consisted of single 22-plant plots, each $14 \mathrm{~m}$ in length. Starting at approximately 40 days after transplanting, the number of plants killed by black shank or bacterial wilt was recorded. This continued throughout the growing season at intervals of approximately 14 days. At the end of the growing season, area under the disease progress curve (AUDPC) was calculated for each plot using the trapezoidal method of Madden et al. (2007).

A population consisting of $180 \mathrm{~F}_{4: 5}$ RILs was generated from a cross between highly bacterial wilt- and black-shank-resistant fluecured tobacco cultivar K346 and disease-susceptible germplasm accession 'TI 1068'. The RIL population and parental lines were evaluated for black shank incidence at the Lower Coastal Plain Research Station and Upper Coastal Plain Research Station during
2014 and 2015 (for a total of four environments). The population was also evaluated for bacterial wilt incidence in a disease nursery at the Upper Coastal Plain Research Station in 2014 and 2015 and in one naturally infested field on a private farm near Selma, NC, in 2015 (for a total of three environments). The experimental design for each environment was a 10-by-18 $\alpha$-lattice with three replications. The two parents were also randomized within each block for a total of 20 entries per block. Experimental units consisted of 12-plant plots of $7 \mathrm{~m}$ in length. Starting at approximately 40 days after transplanting, the number of plants killed by black shank or bacterial wilt was recorded. This continued throughout the growing season at intervals of approximately 14 days. AUDPC was calculated for each plot at the end of the growing season according to Madden et al. (2007).

Statistical analysis. An analysis of variance for AUDPC was performed on the 50 historical lines using PROC MIXED of SAS 9.4 (SAS Institute Inc. 2013) for each disease separately. Genotype was treated as a fixed effect, whereas environment and replication were treated as random effects. Correlation coefficients between entry means for black shank and bacterial wilt AUDPC were calculated using PROC CORR of SAS 9.4.

A square-root transformation was first performed on the AUDPC data from the RIL population to reduce heterogeneity of error variances. ASReml version 3 (Gilmour et al. 2009) was then used to obtain a best linear unbiased prediction (BLUP) for each RIL across all location-year combinations for each disease. A mixed linear model was fit with random effects for RIL, environment, RILenvironment, replication within environment, and block within replication or environment. Variance components estimated from this model were used to calculate heritabilities on an entry mean basis per a univariate mixed-model analysis, as described by Holland et al. (2003). Subsequent QTL analyses were carried out using the BLUPs.

DNA marker genotyping. Leaf tissue samples were collected for the parental lines K346 and TI 1068 and from 10 plants from each $\mathrm{F}_{4: 5}$ family and combined into single tubes. Genomic DNA was isolated using a modified cetyltrimethylammonium bromide procedure (Afandor et al. 1993; Johnson et al. 1995).

The two parental lines were initially genotyped using a total of 825 previously described primer pairs selected to amplify wellspaced microsatellite markers across each $N$. tabacum linkage group (LG) (Bindler et al. 2011). Polymerase chain reactions (PCR) were performed in $10-\mu$ l volumes containing approximately 1 to $15 \mathrm{ng}$ of template DNA, $6 \mu \mathrm{l}$ of True Allele PCR Premix (Life Technologies, Carlsbad, CA), and $10 \mu \mathrm{M}$ each primer. Reaction conditions consisted of 45 PCR cycles at an annealing temperature of $55^{\circ} \mathrm{C}$, according to Bindler et al. (2011). Forward primers were labeled with FAM, HEX, or AT550 for fragment analysis on an Applied Biosystems 3130xL Genetic Analyzer (Life Technologies). Samples containing $1 \mu \mathrm{l}$ of PCR product for each marker, $1 \mu \mathrm{l}$ of Gene Scan 400 HD ROX dye standard (Life Technologies), and $9 \mu 1$ of HiDi formamide (Life Technologies) were denatured for $5 \mathrm{~min}$ at $95^{\circ} \mathrm{C}$. Fragment analysis was performed as a multiloading assay simultaneously analyzing up to three markers labeled with different dyes. Alleles were scored using the GeneMapper 5.0 software package (Life Technologies). Markers identified to be polymorphic between the parental lines were used to genotype the entire RIL population.

Linkage map construction and QTL identification. A linkage map was created with R/qtl (Broman et al. 2003). Heterozygous markers were treated as missing data. Markers with genotypes on less than 130 individuals were excluded from the analysis, as well as lines with genotypes for less than 50 markers. Markers were organized into roughly 24 LG based on a minimum logarithm of odds (LOD) score of 4.5. Marker orders and genetic distances were calculated with the Kosambi mapping function (Kosambi 1943) using ripple and a genotyping error probability of 0.0001 . A final ripple was performed to ensure that the most likely marker order had been selected.

Following linkage map construction, QTL mapping was performed using phenotypic BLUPs for both black shank and bacterial wilt 
resistance using Haley-Knott regression (Haley and Knott 1992) in R/qtl (Broman et al. 2003). QTL were selected using a forward/ backward stepwise model selection approach with the function stepwiseqtl (Broman and Wu 2017). All pairwise interactions were considered but no higher-order interactions were allowed. QTL were identified using a penalized LOD score criterion with three penalties (main effects penalty, heavy penalty on interaction, and light penalty on interaction) (Manichaikul et al. 2009). Values for penalties were calculated from 1,000 permutation results with scantwo. After the model was finalized, the effect of each QTL was estimated using fitqtl.

\section{RESULTS}

Analyses of historical lines. The set of materials outlined in Table 1 was evaluated for black shank resistance in a total of four environments and for bacterial wilt resistance in a total of four

TABLE 1. List of 50 lines of historical importance to flue-cured tobacco breeding that were evaluated for black shank and bacterial wilt resistance ${ }^{\mathrm{a}}$

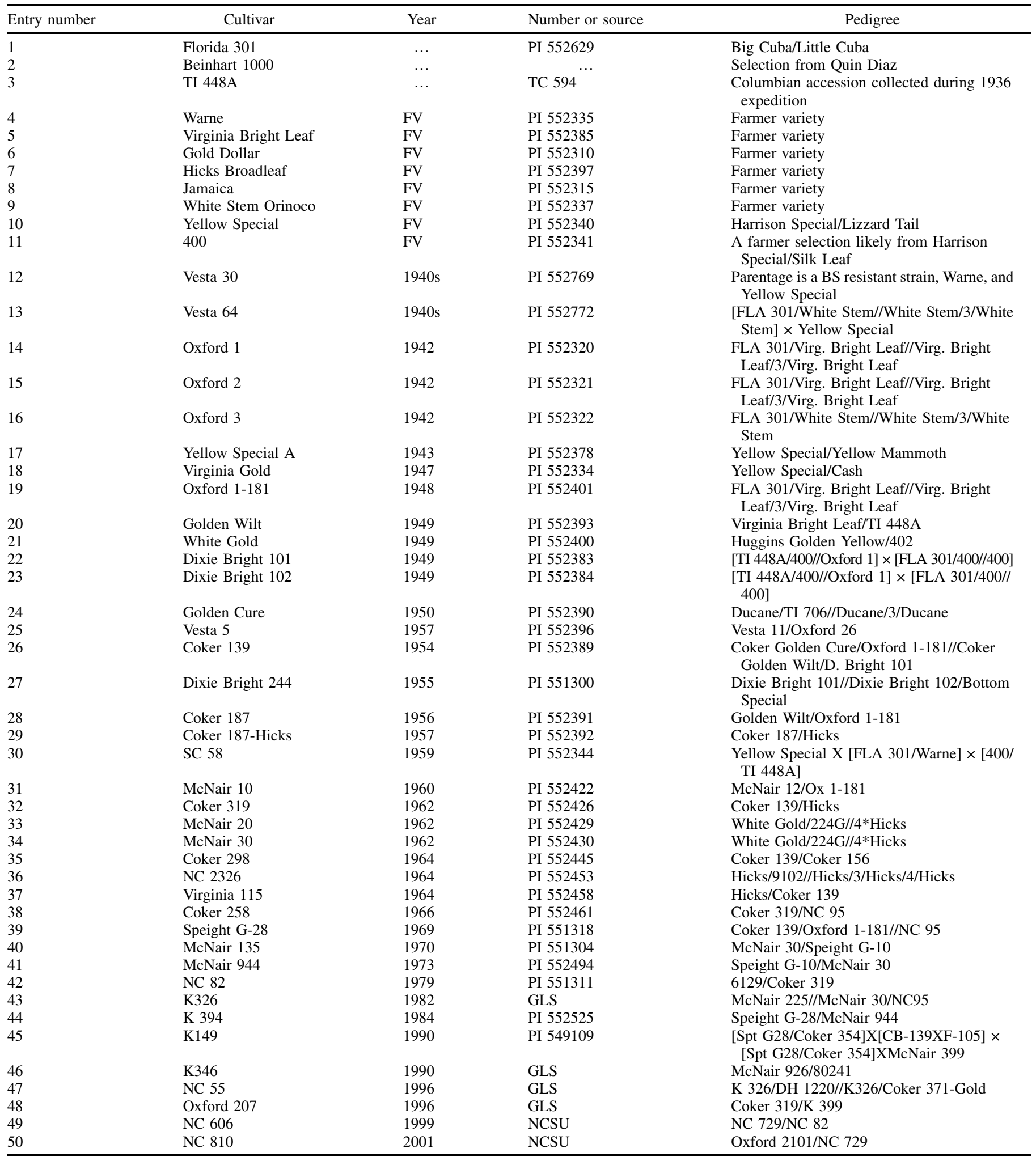

a Abbreviations: FV = farmer variety, GLS = Gold Leaf Seed Company, and NCSU = North Carolina State University. 
environments. Analyses of variance for black shank and bacterial wilt resistance across all environments revealed highly significant differences $(P<0.0001)$ among the 50 entries. Black shank and bacterial wilt resistance for the 50 historical lines, as measured by AUDPC, were highly correlated measured characters; $\mathrm{r}_{\text {Pearson }}=0.85$ $(P<0.0001)$ (Fig. 1). The "farmer" varieties, as a group, were the most susceptible to both soilborne pathogens. Modern flue-cured tobacco cultivars K346 and 'NC606' displayed the best combinations of resistances to both black shank and bacterial wilt.

Analyses of RIL population. Phenotypic evaluation. The set of 180 RIL and their parental lines (K346 and TI 1068) were evaluated for black shank resistance in a total of four environments and for bacterial wilt resistance in a total of three environments. Mixed-model analyses revealed extremely significant differences among the RIL for resistance to both diseases $(P<0.0001)$. Entry mean heritabilities for black shank and bacterial wilt AUDPC were calculated to be $\mathrm{H}=0.95$ (standard error $[\mathrm{SE}]=0.01$ ) and $\mathrm{H}=0.65$ $(\mathrm{SE}=0.05)$, respectively. A high genetic correlation between resistance to the diseases was observed $\left(r_{\mathrm{g}}=0.89 ; P<0.0001\right)$ (Fig. 2$)$.

Genetic linkage map. Of the 825 microsatellite primer pairs tested, $258(31.2 \%)$ were found to produce distinguishable, polymorphic alleles between K346 and TI 1068. In total, 252 markers were used for linkage map construction. The 252 markers were assigned to $24 \mathrm{LGs}$ spanning a total length of 2,020 centimorgans (cM) (Supplementary Fig. S1). The number of markers on each LG ranged from 9 to 13, with an average of 10.5 markers per LG and an average spacing of $8.8 \mathrm{cM}$ per marker. Marker order in this population was largely congruent with the high-density map published by Bindler et al. (2011). Exceptions included the reordering of some markers within an LG, smaller pairwise differences, and a reduced overall map length.

QTL identification in RIL population. Using Haley-Knott regression, the stepwise model selection approach selected a final model for black shank AUDPC that included four QTL located on LG 6, 7, 14, and 23, with no significant QTL-QTL interaction effects (Table 2; Fig. 3). The favorable allele at the QTL on LG 6, 7, and 23 was contributed by K346, whereas the favorable allele at the QTL on LG 14 was contributed by TI 1068. The final model for bacterial wilt AUDPC included three QTL located on LG 6, 7, and 19, also with no significant QTL-QTL interaction effects (Table 2;

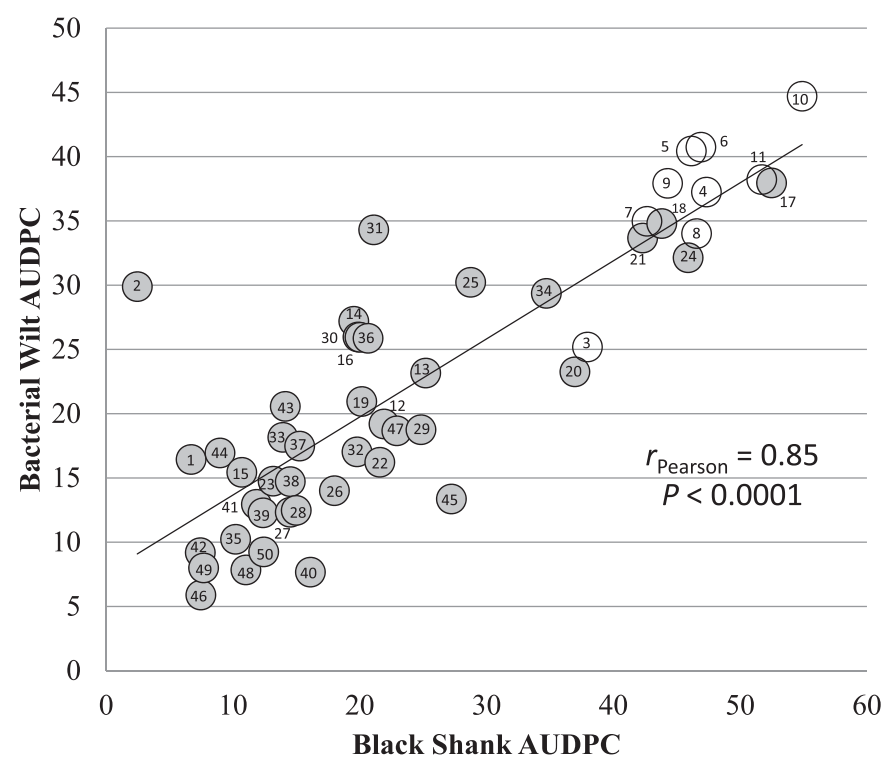

Fig. 1. Area under disease progress curve (AUDPC) means for black shank and bacterial wilt for 50 cultivars or breeding lines of historical breeding importance. Numbers correspond to entry numbers defined in Table 1. White circles correspond to farmer varieties that existed prior to the initiation of science-based tobacco breeding. Shaded circles represent varieties developed via directed hybridization.
Fig. 3). The favorable allele was contributed by K346 for all three QTL. QTL for both black shank and bacterial wilt AUDPC colocalized on the same regions on LG 6 and 7. The QTL on LG 7 explained 38.0 and $32.1 \%$ of the phenotypic variation for black shank and bacterial wilt AUDPC, respectively. The QTL on LG 6 explained 6.1 and $8.4 \%$ of the phenotypic variation for black shank and bacterial wilt AUDPC, respectively. Additional QTL affecting resistance to both diseases explained less than $5 \%$ of the total phenotypic variation. The final QTL model for black shank AUDPC explained $60.0 \%$ of the observed phenotypic variation, whereas the final QTL model for bacterial wilt AUDPC explained 50.3\% of the observed phenotypic variation.

\section{DISCUSSION}

Previous anecdotal evidence suggested a possible genetic relationship between tobacco resistance to black shank and bacterial wilt, caused by the soilborne pathogens $P$. nicotianae and $R$. solanacearum, respectively. We were interested in investigating the genetic control of resistance to both of these diseases using QTL mapping and determining whether there was significant overlap in the genomic regions influencing resistance to each disease. To gain initial insight regarding this question, we evaluated a set of 50 tobacco lines of historical breeding importance. As compared with old-line farmer varieties, tested modern cultivars were found to be much more resistant to both pathogens, thus demonstrating the impact of directed hybridization and selection for disease resistance over decades of science-based tobacco breeding. Cultivars exhibiting high levels of resistance to black shank generally also displayed medium to high levels of resistance to bacterial wilt, and a correlation $\left(\mathrm{r}_{\text {Pearson }}=0.85\right)$ was observed between resistance to both diseases. K346 and NC606 were found to be excellent examples of cultivars with high levels of resistance to both diseases. These findings provided initial support for the hypothesis that at least some tobacco genomic regions controlling resistance to black shank also contribute to bacterial wilt resistance. However, genome-wide genotypes were not available for the set of 50 lines, and some of the observed high correlation could possibly be due to population structure or kinship.

If pleiotropic effects were contributing factors to the strong genetic correlations described above, one would expect the two reported sources of resistance in K346 (Florida 301 for black shank resistance and TI 448A for bacterial wilt resistance) to exhibit some level of resistance to both diseases. As expected, Florida 301 exhibited very high field resistance to black shank but also showed a moderate level of resistance to bacterial wilt. In our experiments,

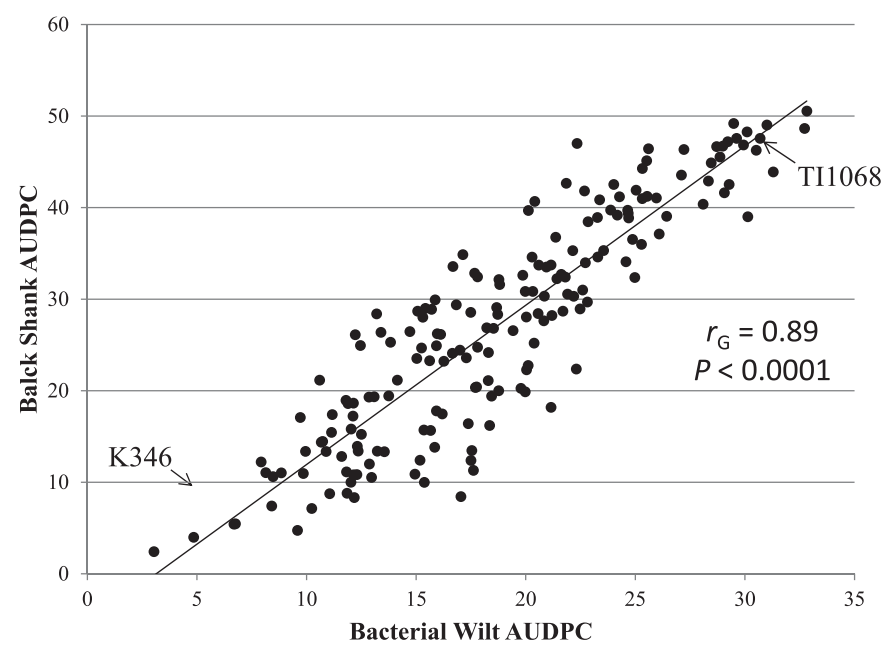

Fig. 2. Area under disease progress curve (AUDPC) means for black shank and bacterial wilt for 180 recombinant inbred lines derived from a cross between K346 and TI 1068. 
however, TI 448A exhibited only low to moderate levels of resistance to bacterial wilt, along with very low levels of resistance to black shank. Reasons for these observations may include (i) the Ralstonia populations are different today than they were in the 1940s when TI 448A was classified as resistant, (ii) TI 448A is not the source of bacterial wilt resistance in K346, (iii) the current seed source for TI 448A in the Nicotiana germplasm collection is not correct, or (iv) the high level of bacterial wilt resistance in varieties such as K346 is due to one or a few TI 448A-derived QTL coupled with a series of additional QTL derived from alternative source material.

To more thoroughly investigate the high level of genetic resistance to both black shank and bacterial wilt in flue-cured tobacco cultivar K346, a mapping population derived from hybridization between K346 and susceptible germplasm accession TI 1068 was studied. The mapping study identified four QTL on LG 6, 7, 14, and 23 associated with black shank resistance and three QTL on LG 6, 7, and 19 associated with resistance to bacterial wilt. The QTL on LG 6 and 7 affecting resistance to both diseases colocalized to the same genomic regions. The QTL identified on LG 7 had the greatest effect and controlled the largest percentage of phenotypic variation for both black shank (38.0\%) and bacterial wilt (32.1\%) resistance. This QTL was also found to have the largest effect on and to control the largest percentage of variation for black shank resistance in a Florida $301 \times$ 'Hicks' RIL population (16.9\%) (Xiao et al. 2013) (Table 2) and a Beinhart $1000 \times$ Hicks doubled-haploid population (25.4\%) (Vontimitta and Lewis 2012b). The number of shared markers between the three studies was limited, making comparison of the location of the associated region somewhat challenging. In both the K346- and Beinhart 1000-derived populations, however, the interval for the QTL was positioned over marker locus PT61472. In the Beinhart 1000- and Florida 301-derived populations, the interval was positioned over marker locus PT30174, suggesting a role for the same region in each population. The identification of this QTL in a third population provides further validation for the position and importance of allelic variation in this region in black shank resistance in $N$. tabacum. Given the confirmed importance of the QTL on LG 7 for black shank resistance in combination with newfound importance it has on bacterial wilt resistance, fine mapping this interval for resistance to both soilborne diseases would be valuable for moving in the direction of the identification of the genes underlying this QTL. Indeed, this work is already underway (Ma 2017) and should aid in the transfer of soilborne disease resistance to other cultivars and provide insight regarding the question of linkage versus pleiotropy as reasons contributing to the correlation between the two traits.

The QTL on LG 6 had an intermediate effect for both diseases, explaining 6.1 and $8.1 \%$ of the phenotypic variation in black shank and bacterial wilt, respectively. A QTL on LG 6 was also found to have an intermediate effect on bacterial wilt resistance $(5.4 \%)$ in a 'Yanyan 97' (which has TI 448A in its pedigree) $\times$ 'Honghua Dajinyuan' $F_{2: 3}$ mapping population (Lan et al. 2014), and to have an intermediate effect on black shank resistance $(7.1 \%)$ in a Florida $301 \times$ Hicks RIL mapping population (Xiao et al. 2013). The fact that few markers were shared between these studies again makes comparison difficult but the confidence interval for this QTL was positioned over marker TM10089 in both the Yanyan 97 and Florida 301 populations, strengthening the evidence for the importance of this region for both black shank and bacterial wilt resistance.

Surprisingly, a QTL on LG 24 was identified in both the Florida 301 and Beinhart 1000 black shank resistance mapping studies as well as in the Yanyan 97 bacterial wilt resistance mapping study but not in the current K346 mapping study. Limited overlapping markers make it difficult to determine whether the same region on LG 24 was identified in all three studies but this seems likely. K346 is representative of modern flue-cured tobacco cultivars possessing high levels of polygenic resistance to multiple soilborne pathogens. Because this QTL was not identified in the K346 mapping population (Table 2), it suggests that this region may not have been incorporated in modern U.S. cultivars. High-density genotyping of the 50 historical lines in the genomic regions of interest would help confirm this speculation. If modern varieties do not carry an incorporated Florida 301 region at this genomic location, it could be utilized as a novel source of resistance to both black shank and bacterial wilt. Markers associated with this region could be useful in transferring this resistance to desired genetic backgrounds. Given the low to moderate effect associated with this QTL in the other populations, it would be most useful in backgrounds that already possess the QTL on LG 6 and 7.

The finding that the two largest QTL affecting resistance to black shank in the K346 $\times$ TI 1068 population overlapped almost perfectly with the two QTL with greatest effects against bacterial wilt in the same population is interesting. Further study is necessary to determine whether this relationship is due to the same genes affecting resistance to both diseases (i.e., pleiotropy) or due to the result of favorable coupling phase linkages that were produced via selective breeding. The concept of MDR has recently been reviewed by Wiesner-Hanks and Nelson (2016). Lines exhibiting MDR could contain many genes acting independently to confer resistance, or single genes conferring resistance to multiple pathogens. Single genomic regions and single genes conferring resistance to multiple plant pests have recently been identified. For example, the qualitative Mi- 1 gene of tomato confers resistance to both the root-knot nematode and potato aphid (Rossi et al. 1998), and the RPS1 and RPS4 Arabidopsis genes work together to confer resistance to both fungal and bacterial pathogens (Colletotrichum higginsanum, Pseudomonas syringae, and $R$. solanacearum) (Narusaka et al. 2009). Quantitative resistance loci associated with MDR have also been reported in crops

TABLE 2. Summary of quantitative trait loci results for evaluation of tobacco mapping populations for soilborne disease resistance

\begin{tabular}{|c|c|c|c|c|c|c|c|c|c|c|c|c|c|c|c|c|c|c|}
\hline \multirow[b]{3}{*}{$\begin{array}{l}\text { Linkage } \\
\text { group }^{\mathrm{a}}\end{array}$} & \multicolumn{12}{|c|}{ K346 $\times$ TI1068 recombinant inbred line mapping population } & \multirow{2}{*}{\multicolumn{6}{|c|}{$\frac{\text { Florida } 301 \times \text { Hicks mapping population }^{\mathrm{c}}}{\text { Black shank resistance }}$}} \\
\hline & \multicolumn{6}{|c|}{ Black shank resistance } & \multicolumn{6}{|c|}{ Bacterial wilt resistance } & & & & & & \\
\hline & $\begin{array}{c}\text { Left } \\
\text { marker }\end{array}$ & $\begin{array}{l}\text { Right } \\
\text { marker }\end{array}$ & $\mathrm{cM}$ & $\begin{array}{c}\text { Effect } \\
(\text { sqAUDPC })^{b}\end{array}$ & LOD & $R^{2}$ & $\begin{array}{c}\text { Left } \\
\text { marker }\end{array}$ & $\begin{array}{c}\text { Right } \\
\text { marker }\end{array}$ & $\mathrm{cM}$ & $\begin{array}{c}\text { Effect } \\
(\text { sqAUDPC) }\end{array}$ & LOD & $R^{2}$ & $\begin{array}{c}\text { Left } \\
\text { marker }\end{array}$ & $\begin{array}{l}\text { Right } \\
\text { marker }\end{array}$ & $\mathrm{cM}$ & $\begin{array}{c}\text { Effect } \\
(\text { AUDPC) }\end{array}$ & LOD & $R^{2}$ \\
\hline 7 & PT61472 & PT52970 & 6.6 & $-0.83^{\mathrm{d}}$ & 25.4 & 38.0 & PT61472 & PT52970 & 6.6 & -0.45 & 19.1 & 32.1 & РT30174 & РT30165 & 62.0 & -45.09 & 8.79 & 16.9 \\
\hline 24 & & & & & & & & & & & & & TME0466 & PT60308 & 9.5 & -32.09 & 3.52 & 9.2 \\
\hline 6 & PT61581 & PT50885 & 71.0 & -0.42 & 5.4 & 6.1 & PT61581 & PT50885 & 69.0 & -0.28 & 6.0 & 8.4 & TM10470 & TM10922 & 67.4 & -28.24 & 4.19 & 7.1 \\
\hline 24 & & & & & & & & & & & & & PT51264 & PT61153 & 37.3 & -26.29 & 2.60 & 6.1 \\
\hline 19 & & & & & & & PT60099 & PT53353 & 87.7 & -0.18 & 4.0 & 5.5 & & & & & & \\
\hline 14 & PT53339 & PT53687 & 60.8 & 0.29 & 4.4 & 4.4 & & & & & & & TM10552 & TM10983 & 4.9 & -28.05 & 3.17 & 6.0 \\
\hline 4 & & & & & & & & & & & & & TM10821 & TM10914 & 83.8 & -24.96 & 2.79 & 4.2 \\
\hline 23 & PT54270b & РT50062 & 0.0 & -0.28 & 4.0 & 4.0 & & & & & & & & & & & & \\
\hline 22 & & & & & & & & & & & & & TM10368 & TM11161 & 33.6 & -22.69 & 2.49 & 3.7 \\
\hline 20 & & & & & & & & & & & & & TME0324a & TM10386 & 15.1 & -25.30 & 3.21 & 4.3 \\
\hline
\end{tabular}

a Linkage groups correspond to those published by Bindler et al. (2011).

b sqAUDPC indicates the effect for square root-transformed area under the disease progress curve data.

c Data from Xiao et al. (2013).

d Negative effect indicates that the favorable allele was derived from K346 or Florida 301. 
such as rice, where overlapping QTL affecting resistance to rice blast, sheath blight, and bacterial blight were detected on the same chromosome segment (Wisser et al. 2005). In addition, multiple genomic regions were found to be associated with gray leaf spot, northern leaf blight, and southern leaf blight in maize (Wisser et al. 2011; Zwonitzer et al. 2010). The marker-trait associations identified here, coupled with the recently published increased-quality N. tabacum genome sequence (Edwards et al. 2017), should be useful for further studies to determine whether the overlap of bacterial wilt and black shank resistance QTL on $N$. tabacum LG 6 and 7 is due to genes with pleiotropic effects or due to favorable coupling phase genetic linkages that were generated via selective breeding.

The data reported here describe a polygenic system contributing to the high levels of field resistance to bacterial wilt in K346 fluecured tobacco. Bacterial wilt resistance in the Solanaceae family has been most thoroughly investigated in tomato, where resistance appears to be controlled in a manner similar to that in tobacco. In tomato, bacterial wilt resistance is largely quantitative in nature, with many QTL mapped and no major resistance genes identified (Thoquet et al. 1996a,b; Wang et al. 2000, 2013; Young and Danesh 1994). Both strain-specific and broad-spectrum QTL have been
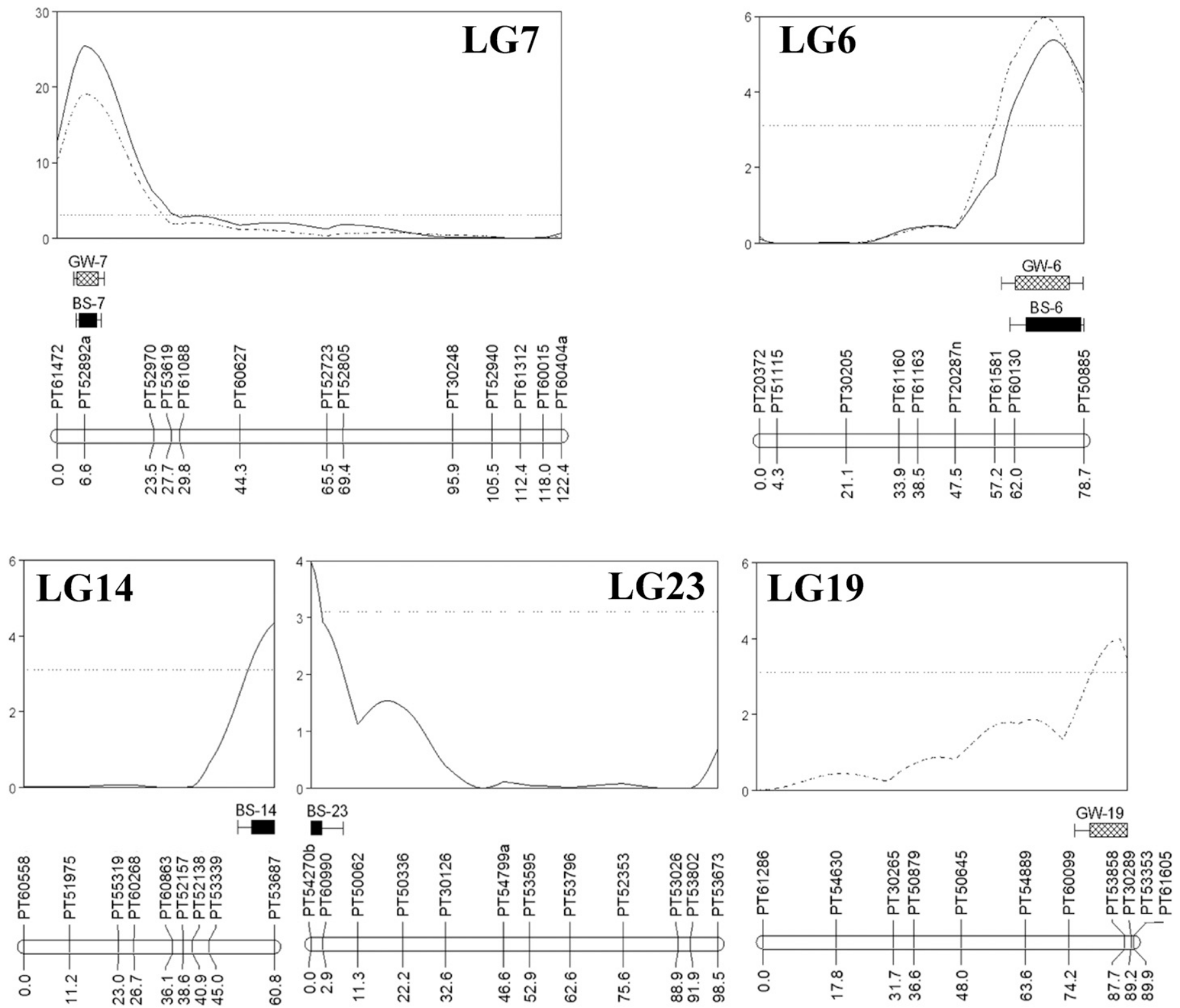

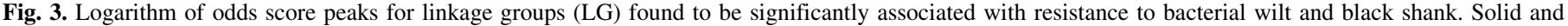
dashed lines relate to data for black shank and bacterial wilt, respectively. 
contributing to high levels of partial resistance to soilborne pathogens in N. tabacum.

\section{LITERATURE CITED}

Afandor, L. K., Haley, S. D., and Kelly, J. D. 1993. Adoption of a "mini-prep" DNA extraction method for RAPD marker analysis in common bean (Phaseolus vulgaris L.). Annu. Rep. Bean Improv. Coop. 36:10-11.

Apple, J. L. 1962. Transfer of resistance to black shank (Phytophthora parastica var. nicotianae) from Nicotiana plumbaginifolia to $\mathrm{N}$. tabacum. (Abstr.) Phytopathology 52:1.

Bindler, G., Plieske, J., Bakaher, N., Gunduz, I., Ivanov, N., Van der Hoeven, R., Ganal, M., and Donini, P. 2011. A high density genetic map of tobacco (Nicotiana tabacum L.) obtained from large scale microsatellite marker development. Theor. Appl. Genet. 123:219-230.

Broman, K.W., and Wu, H. 2017. Package "qtl." CRAN. https://cran.r-project. org/web/packages/qtl/qtl.pdf

Broman, K. W., Wu, H., Sen, Ś., and Churchill, G. A. 2003. R/qtl: QTL mapping in experimental crosses. Bioinformatics 19:889-890.

Carmeille, A., Caranta, C., Dintinger, J., Prior, P., Luisetti, J., and Besse, P. 2006. Identification of QTLs for Ralstonia solanacearum race 3-phylotype II resistance in tomato. Theor. Appl. Genet. 113:110-121.

Chaplin, J. F. 1962. Transfer of black shank resistance from Nicotiana plumbaginifolia to flue-cured $N$. tabacum. Tob. Sci. 6:184-189.

Chaplin, J. F. 1966. Comparison of tobacco black shank (Phytophthora parasitica var. nicotianae) resistance from four sources. Tob. Sci. 10:55-58.

Drake, K., and Lewis, R. S. 2013. An introgressed genomic region confers resistance to Phytophthora nicotianae in cultivated tobacco. Crop Sci. 53:1366-1374.

Drake, K. E., Moore, J. M., Bertrand, P., Fortnum, B., Peterson, P., and Lewis, R. S. 2015. Black shank resistance and agronomic performance of flue-cured tobacco lines and hybrids carrying the introgressed region, Wz. Crop Sci. 55:79-86.

Edwards, K. D., Fernandez-Pozo, N., Drake-Stowe, K., Humphry, M., Evans, A. D., Bombarely, A., Allen, R., Hurst, R., White, B., Kernodle, S. P., Bromley, J. R., Sanchez-Tamburrino, J. P., Lewis, R. S., and Mueller, L. A. 2017. A reference genome for Nicotiana tabacum enables map-based cloning of homeologous loci implicated in nitrogen utilization efficiency. BMC Genomics 18:448.

Gilmour, A. R., Gogel, B. J., Cullis, B. R., and Thompson, R. 2009. ASReml User Guide Release 3.0. VSN International Ltd., Hemel, Hempstead HP1 1ES, UK.

Haley, C., and Knott, S. 1992. A simple regression method for mapping quantitative trait loci in line crosses using flanking markers. Heredity 69:315-324.

Holland, J. B., Nyquist, W. E., and Cervantes-Martínez, C. T. 2003. Estimating and interpreting heritability for plant breeding: An update. Pages 9-112 in: Plant Breeding Reviews, Vol. 22. J. Janick, ed. John Wiley \& Sons, Inc.

Hong, J. C., Norman, D. J., Reed, D. L., Timur Momol, M., and Jones, J. B. 2012. Diversity among Ralstonia solanacearum strains isolated from the southeastern United States. Phytopathology 102:924-936.

Johnson, E., Miklas, P. N., Stavely, J. R., and Martinez-Cruzado, J. C. 1995. Coupling-phase and repulsion-phase RADPs for marker assisted selection. Theor. Appl. Genet. 90:659-664.

Katawczik, M., and Mila, A. L. 2012. Plant age and strain of Ralstonia solanacearum affect the expression of resistance of tobacco cultivars to Granville wilt. Tob. Sci. 49:8-13.

Katawczik, M., Tseng, H. T., and Mila, A. L. 2016. Diversity of Ralstonia solanacearum populations affecting tobacco crops in North Carolina. Tob. Sci. 53:1-11

Kim, B.-S., French, E., Caldwell, D., Harrington, E. J., and Iyer-Pascuzzi, A. S. 2016. Bacterial wilt disease: Host resistance and pathogen virulence mechanisms. Physiol. Mol. Plant Pathol. 95:37-43.

Kosambi, D. D. 1943. The estimation of map distances from recombination values. Ann. Eugen. 12:172-175.

Lan, T., Zheng, S., Yang, L., Wu, S., Wang, B., Zhang, S., Tong, Z., Chen, Y., Chen, S., Duan, Y., and Wu, W. 2014. Mapping of quantitative trait loci conferring resistance to bacterial wilt in tobacco (Nicotiana tabacum L.). Plant Breed. 133:672-677.

Ma, J. M.-Y. 2017. The fine mapping of two black shank resistance loci and identification of a hybrid lethality gene in tobacco. Unpublished $\mathrm{Ph} . \mathrm{D}$. dissertation, North Carolina State University.

Madden, L. V., Hughes, G., and van den Bosch, F. 2007. Study of Plant Disease Epidemics. American Phytopathological Society, St. Paul, MN.

Manichaikul, A., Moon, J. Y., Sen, S., Yandell, B. S., and Broman, K. W. 2009. A model selection approach for the identification of quantitative trait loci in experimental crosses, allowing epistasis. Genetics 181:1077-1086.
Matsuda, T. 1977. Fundamental studies on the breeding of bacterial wilt resistant varieties in tobacco. Bull. Utsunomiya Tob. Exp. Stn. 15:1-95. (English summary).

Matsuda, T., and Ohashi, Y. 1973. Inheritance of resistance to bacterial wilt in tobacco. Jpn. J. Breed. 23:175-180.

Narusaka, M., Shirasu, K., Noutoshi, Y., Kubo, Y., Shiraishi, T., Iwabuchi, M., and Narusaka, Y. 2009. RRS1 and RPS4 provide a dual resistance-gene system against fungal and bacterial pathogens. Plant J. 60:218-226.

North Carolina Cooperative Extension. 2015. Flue-Cured Tobacco Guide. North Carolina State University, Raleigh.

Rossi, M., Goggin, F. L., Milligan, S. B., Kaloshian, I., Ullman, D. E., and Williamson, V. M. 1998. The nematode resistance gene $M i$ of tomato confers resistance against the potato aphid. Proc. Natl. Acad. Sci. USA 95:9750-9754.

SAS Institute Inc. 2013. SAS 9.4 Procedures Guide: Statistical Procedures, 2nd ed. SAS Institute Inc., Cary, NC.

Smith, T., and Clayton, E. E. 1948. Inheritance of resistance to bacterial wilt in tobacco. J. Agric. Res. 76:27-32.

Sullivan, M. J., Melton, T. A., and Shew, H. D. 2005. Managing the race structure of Phytophthora parasitica var. nicotianae with cultivar rotation. Plant Dis. 89:1285-1294.

Thoquet, P., Olivier, J., Sperisen, C., Rogowsky, P., Laterrot, H., and Grimsley, N. 1996a. Quantitative trait loci determining resistance to bacterial wilt in tomato cultivar Hawaii7996. Mol. Plant-Microbe Interact. 9:826-836.

Thoquet, P., Olivier, J., Sperisen, C., Rogowsky, P., Prior, P., Anais, G., Mangin, B., Bazin, B., Nazer, R., and Grimsley, N. 1996b. Polygenic resistance of tomato plants to bacterial wilt in the French West Indies. Mol. Plant-Microbe Interact. 9:837-842.

Tisdale, W. B. 1931. Development of strains of cigar wrapper tobacco resistant to black shank (Phytophthora nicotianae Breda de Haan). Fla. Agric. Exp. Stn. Bull. 226:1-45.

Valleau, W., Stokes, G. W., and Johnson, E. M. 1960. Nine years experience with the Nicotiana longiflora factor for resistance to Phytophthora parasitica var. nicotianae in control of black shank. Tob. Sci. 4:92-94.

Valleau, W. D. 1952. Breeding tobacco for disease resistance. Econ. Bot. 6:69-102.

Vontimitta, V., and Lewis, R. S. 2012a. Mapping of quantitative trait loci affecting resistance to Phytophthora nicotianae in tobacco (Nicotiana tabacum L.) line Beinhart-1000. Mol. Breed. 29:89-98.

Vontimitta, V., and Lewis, R. S. 2012b. Growth chamber evaluation of a $\mathrm{Ni}$ cotiana tabacum 'Beinhart 1000 ' $\times$ 'Hicks' mapping population for QTL affecting resistance to multiple races of Phytophthora nicotianae. Crop Sci. 52:91-98.

Wang, J. F., Ho, F.-I., Truong, H. T. H., Hugan, S.-M., Balatero, C. H., Dittapongpitch, V., and Hidayati, H. 2013. Identification of major QTLs associated with stable resistance of tomato cultivar 'Hawaii 7996' to Ralstonia solanacearum. Euphytica 190:241-252.

Wang, J. F., Olivier, J., Thoquet, P., Mangin, B., Sauviac, L., and Grimsley, N. H. 2000. Resistance of tomato line Hawaii7996 to Ralstonia solanacearum Pss4 in Taiwan is controlled mainly by a major strain-specific locus. Mol. Plant-Microbe Interact. 13:6-13.

Wiesner-Hanks, T., and Nelson, R. 2016. Multiple disease resistance in plants. Annu. Rev. Phytopathol. 54:229-252.

Wisser, R. J., Kolkman, J. M., Patzoldt, M. E., Holland, J. B., Yu, J., Karakowsky, M., Nelson, R. J., and Balint-Kurti, P. J. 2011. Multivariate analysis of maize disease resistances suggests a pleiotropic genetic basis and implicates a GST gene. Proc. Natl. Acad. Sci. USA 108:7339-7344.

Wisser, R. J., Sun, Q., Hulbert, S. H., Kresovich, S., and Nelson, R. J. 2005. Identification and characterization of regions of the rice genome associated with broad-spectrum, quantitative disease resistance. Genetics 169: 2277-2293.

Xiao, B., Drake, K., Vontimitta, V., Tong, Z., Zhang, X., Li, M., Leng, X., Yongpi, L., and Lewis, R. S. 2013. Location of genomic regions contributing to resistance in tobacco cultivar Florida 301. Crop Sci. 53:473-481.

Young, N. D., and Danesh, D. 1994. Understanding bacterial wilt resistance in tomato through the use of DNA genetic-markers. Pages 145-156 in: Bacterial Wilt: The Disease and its Causative Agent, Pseudomonas solanacearum. A. C. Hayward, G. L. Hartman, and Asian Vegetable Research and Development Center, eds. CAB International, Wallingford, UK.

Zwonitzer, J. C., Coles, N. D., Krakowsky, M. D., Arrellano, C., Holland, J. B., McMullen, M. D., Pratt, R. C., and Balint-Kurti, P. J. 2010. Mapping resistance quantitative trait loci for three foliar diseases in a maize recombinant inbred line population-Evidence for multiple disease resistance? Phytopathology 100:72-79. 